Silva, G.V.; Pontes, A.N.; Pereira, A.M.; Lima, A.M.M. Contribuições da Educação Ambiental para o turismo em Bragança (PA) (Amazônia Atlântica): uma perspectiva participativa. Revista Brasileira de Ecoturismo, São Paulo, v.6, n.3, ago/out-2013, pp.778-799.

\title{
Contribuições da Educação Ambiental para o turismo em Bragança (PA) (Amazônia Atlântica): uma perspectiva participativa
}

\author{
Contributions of Environmental Education for tourism in Bragança (PA, Brazil) \\ (Amazon rainforest): a participatory approach \\ Glauce Vitor da Silva, Altem Nascimento Pontes, \\ Alexandre Macedo Pereira, Aline Maria Meiguins de Lima
}

\begin{abstract}
RESUMO
O turismo envolve diversos atores e segmentos da sociedade, além de investimentos em programas, projetos e produtos. Tais investimentos apresentam dinâmicas de interesses e benefícios diferentes, dependendo dos envolvidos (governo, comunidades, áreas protegidas, setor privado). Essa divergência ou convergência de interesses promove discussões sobre os efeitos desta atividade em relação aos recursos naturais. Um exemplo disso é o turismo da zona costeira que contém ambientes vulneráveis às ações antrópicas. Neste estudo, avaliou-se o município de Bragança (polo turístico Amazônia Atlântica no litoral nordeste do Pará), que apresenta como principal atrativo para a atividade turística o seu patrimônio cultural e paisagístico. A partir disso, foi proposta a discussão da relação entre as práticas de turismo desenvolvidas no município de Bragança e a demanda por ações de educação ambiental como um instrumento de construção de uma gestão participativa do turismo local. A pesquisa teve como objetivo identificar, no município, as variáveis de maior significado para uma análise das consequências sociais e ambientais da atividade de turismo, como as suas forças motoras, onde ocorre a maior pressão, as situações decorrentes, os impactos socioambientais gerados e as respostas possíveis de intervenção. Nesta abordagem, focalizou-se o papel da educação ambiental como instrumento de gestão social. Os resultados mostraram que a região sofre com elementos potenciais de pressão, principalmente pela necessidade de expandir a atividade de turismo em função da demanda por geração de emprego e renda. Logo, a educação ambiental deveria atuar como instrumento de articulação e mobilização para ampliar as discussões acerca das consequências dessas ações no município e sobre os sistemas naturais, incentivando o diálogo entre os atores envolvidos e fomentando a agregação de valor ao patrimônio existente, em favor de sua preservação.
\end{abstract}

PALAVRAS-CHAVE: Educação Ambiental; Gestão Participativa; Atividade Turística. 


\begin{abstract}
Tourism involves several actors and segments of society, as well as investments in programs, projects and products. These investments present dynamics of interests and different benefits, depending on the involved (government, communities, protected areas, private sector). This divergence or convergence of interests promotes discussions about the effects of this activity in relation to natural resources. One example of this is coastal zone tourism which contains environments vulnerable to anthropic actions. In this study, we evaluated the municipality of Bragança (tourist pole Atlantic Amazon in northeast coast of Pará), which presents as main attraction for tourist activity your cultural heritage and scenic. From this, it was proposed the discussion of the relation between tourism practices developed in the municipality of Bragança and the demand for environmental education actions as an instrument for construct a participatory management of local tourism. The research aimed to identify, in the municipality, the variables of greatest significance for an analysis of the social and environmental consequences of tourism activity, as its driving forces, where occurs higher pressure, situations arising, the socioenvironmental impacts generated and possible answers for intervention. In this approach, has focused on the role of environmental education as an instrument of social management. The results showed that the region suffers with potential elements of pressure, mainly by the need to expand the tourism activity due to the demand for employment and income generation. Therefore, the environmental education should act as a means of coordination and mobilization to broaden the discussion about the consequences of these actions in the municipality and on natural systems, encouraging dialogue between the actors involved and promoting value addition the existing patrimony in favor of its preservation.
\end{abstract}

KEYWORDS: Environmental Education; Participatory Management; Tourist Activity.

\title{
Introdução
}

O turismo é um conjunto das relações e experiências que se produzem como consequência da atividade. Para atingir a sustentabilidade no turismo é indispensável o esforço integrado dos atores desse processo, que buscarão associar os recursos naturais e culturais em uma ação de planejamento que estabeleça um desenvolvimento gradual e permanente, além de equitativo, do ponto de vista social, viável economicamente e comprometido com a preservação ambiental (IGNARRA, 2003).

De acordo com Trigo e Mazaro (2012), o turismo é uma atividade que pode trazer consequências que alteram o modo de vida de uma sociedade, seja de forma positiva: criação de empregos, geração de impostos e promoção do desenvolvimento, por exemplo; ou negativa: poluição, exclusão social, concentração de renda, aumento da prostituição e exploração sexual de crianças e adolescentes, entre outros. A responsabilidade por essas questões não é exclusiva dos governos (federal, estadual ou municipal), mas também da sociedade civil organizada como um todo.

O avanço dessa atividade não tem ocorrido de forma homogênea e igualitária, espacial e territorialmente, ao longo dos anos (CACHO; AZEVEDO, 2010). Os motivos são diversos, mas acabam se enquadrando dentro da relação sociedade versus patrimônio natural. Porém, um fato é perceptível, a contínua demanda do turismo pelo acesso à informação (NECHAR, 2011). Este avanço possibilitou que a sociedade se tornasse mais participativa no processo de construção das políticas públicas voltadas para o setor (PLASTINO et al., 2010; ESPÍNOLA; CASTRO, 2012; SILVA et al., 2012), visto que esta tem acesso rapidamente à informação e às consequências da implantação dos projetos 
em uma região.

No processo de construção das políticas públicas de turismo, a gestão participativa busca estabelecer diretrizes para o crescimento ordenado do setor. Para tanto, faz-se necessário planejar, o que significa equilibrar o atendimento às necessidades do turista e propiciar o bem estar de todos os sujeitos sociais envolvidos, o que implica em recompensar a comunidade que divide seu espaço com os turistas, financiando, com os recursos provenientes do turismo, as ações requeridas para melhorar a qualidade de vida dessa comunidade (SEVERINO; TOMASULO, 2012).

No alcance desta meta, destacam-se a necessidade de cultivar a conscientização da comunidade quanto ao valor e à necessidade de proteção do patrimônio natural e cultural, assim como os padrões de sustentabilidade de um crescimento local apropriado; além de envolver as pessoas nos planos de conservação e na gestão da área (AGUIAR et al., 2010).

Um dos meios para se resgatar valores fundamentais para a conservação e para um convívio harmônico entre diferentes culturas e entre essas e a natureza é a educação ambiental (SILVA, 2011), que surge como uma alternativa para a gestão ambiental associada à atividade turística. É importante promover ações estratégicas no planejamento turístico local, a fim de buscar valorizar a natureza, respeitar os limites de crescimento, buscar participação, democratização e emancipação igualitária (RABINOVICI, 2008).

A educação ambiental tem como objetivo central criticar o modelo de desenvolvimento capitalista, tendo em vista que esse modelo concebe a natureza como "recurso" natural e coisifica o homem em razão do lucro (LEFF, 2003). Ela se recusa a adotar práticas/ações pragmáticas que coloquem as populações vulneráveis como responsáveis pelos impactos ambientais e humanos (MÉSZÁROS, 2002).

No Século XX, a educação ambiental consagrou-se como instrumento de integração com uma diversidade de práticas e correntes que espelham bem a complexidade de contextos, problemas e visões da atualidade, incluindo as zonas costeiras. Dessas práticas e correntes teóricas, citam-se, segundo Carvalho et al (2011): a Naturalista (a qual busca reconstruir uma ligação com a natureza); a Conservacionista (de gestão); a Biorregionalista (ligada ao desenvolvimento comunitário, local e regional); a Crítica (que se volta para a investigação sobre a realidade e a resolução de problemas); e a Etnográfica (que valoriza a dimensão cultural).

Fortunato (2009) defende a ideia de que a educação ambiental e a atividade turística se assemelham, à medida que ambas estão preocupadas com as questões cotidianas e desejam contribuir com a melhoria do lugar onde se instituem, estabelecendo, assim, paralelos indissociáveis.

A partir do histórico de implantação do turismo no Brasil (TRIGO; MAZARO, 2012), observa-se que existe o confronto de duas realidades distintas: de um lado, os empreendimentos autárquicos, isolados e sem relações vinculantes com as comunidades do território onde estão situados; de outro, os empreendimentos associados a um planejamento envolvendo a gestão social (FABRINO et al., 2012). A implantação do turismo como atividade produtiva e o desenvolvimento local sustentável na região amazônica representam exemplos desta discussão. 


\section{Caracterização da área de estudo}

A Amazônia brasileira passou a ser conhecida como Amazônia Legal a partir da Lei 1.806/53, consequência de um conceito político e não geográfico advindo da necessidade do governo de planejar e promover o desenvolvimento da região. De acordo com o Art. 2ํㅜ desta lei, para efeito de planejamento econômico, a Amazônia Legal abrange a região compreendida pelos estados do Pará e do Amazonas, pelos territórios federais do Acre, Amapá, Guaporé e Rio Branco e, ainda, e partes dos estados de Mato Grosso, de Goiás e do Maranhão.

O Pará é a segunda maior unidade federativa do Brasil, com mais de um miIhão de quilômetros quadrados. Segundo Santos e Santana (2009), 23,7\% das áreas de florestas naturais da Amazônia Legal estão localizadas no estado.

A Amazônia Legal, em toda a sua extensão territorial, apresenta uma diversidade de sistemas hídricos, de fauna/flora, de paisagens, extenso acervo arquitetônico Português, Francês e Espanhol, conjunto de museus, além de ampla diversidade cultural de seus povos, constituindo-se, assim, em uma região com extraordinário potencial turístico. O Pará contém parte desse acervo, destacando-se a forte relação do território com os sistemas hídricos existentes.

Neste enfoque, o presente trabalho aborda uma região bem específica, que é a zona costeira do estado Pará, onde o governo estadual implantou o Polo Turístico Amazônia Atlântica (PARÁ, 2001). Esse polo é constituído pelos municípios de: Vizeu, Augusto Corrêa, Bragança, Tracuateua, Salinópolis, São João de Pirabas, Primavera, Santarém Novo, Maracanã, Marapanim, Curuçá, Vigia, Colares, Magalhães Barata, São Caetano de Odivelas, São João da Ponta e Quatipuru.

O Polo Turístico Amazônia Atlântica está situado na faixa do litoral atlântico do Pará, no nordeste do estado. De acordo com Pereira et al. (2006a), a região ou zona do salgado, como também é conhecida a área litorânea paraense, está protegida da descarga das águas barrentas do rio Amazonas pela Ilha do Marajó e pela vazão do rio Pará.

Segundo Sousa et al. (2008), a costa amazônica apresenta características hidrodinâmicas e climatológicas únicas no Brasil. O encontro da floresta amazônica com o oceano Atlântico propicia um cenário singular, com características específicas e com potencialidades à prática do turismo. Neste artigo é discutido o potencial de um dos municípios mais tradicionais do estado, localizado na zona do salgado (Polo Turístico Amazônia Atlântica), que é Bragança, cuja sede municipal foi criada pela lei Provincial n. 252, de 2 de outubro de 1854, conforme indica a Figura 1.

Em 2009, Bragança ficou entre os 21 municípios do Pará que receberam o título de Município Turístico, pela Companhia Paraense de Turismo (PARATUR), por alcançar uma pontuação significativa pela Resolução n. ${ }^{\circ}$ 002/09 desta Instituição. Bragança é conhecida como a "Pérola do Caeté", por sua localização às margens do rio Caeté. O município possui em seu território belas praias, monumentos históricos, manguezais, rios, igarapés, ilhas e uma forte cultura, que formam um cenário especial à visitação. 


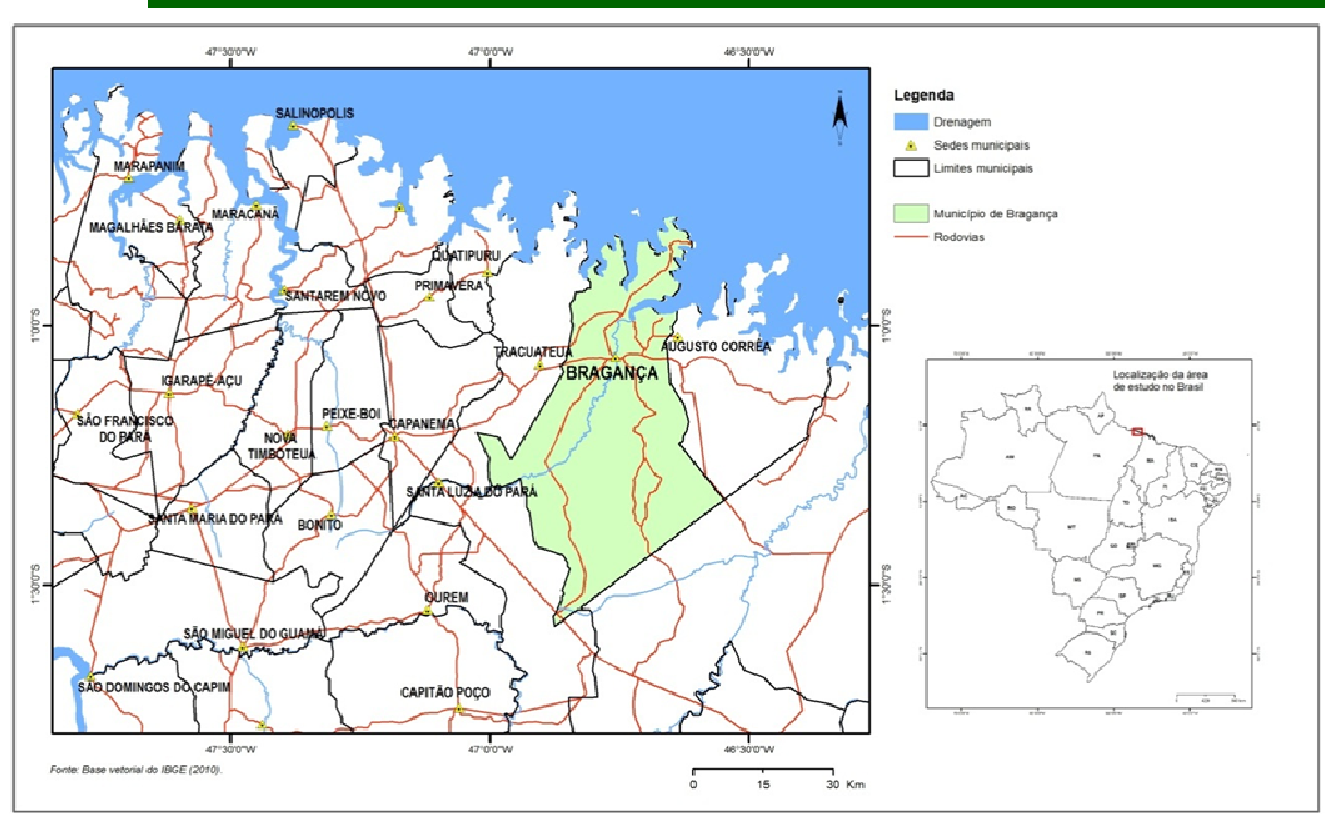

Figura 1: Município de Bragança na zona costeira do Pará. Fonte: autores.

Figura 1: Municipality of Bragança in the coastal zone of Pará. Source: by authors.

A gestão participativa não se centra em grandes investimentos econômicos, mas na participação efetiva das populações no processo de planejamento, execução e monitoramento das atividades nessas localidades (ESPÍNOLA; CASTRO, 2012). Nesse processo, a educação ambiental desempenha um papel importante.

A educação ambiental e a relação entre o turismo e o meio ambiente têm sido foco de estudos em várias publicações (LEAL-FILHO, 2005; NEIMAN; RABINOVICI, 2008; FORTUNATO, 2009; SANDEVILLE JR et al., 2010; SILVA, 2011; ESPÍNOLA; CASTRO, 2012) que se caracterizam por enfatizar a importância de articulação e envolvimento dos atores envolvidos direta ou indiretamente com a atividade turística, além da contribuição da educação ambiental para a prática do turismo pautada na sustentabilidade.

Ruschmann (2001) considera que, enquanto a indústria destrói para produzir, o turismo deve preservar para produzir, pois a atividade depende da harmonia do ambiente, sendo que a degradação deste afeta a competitividade do turismo local. Tal fato contrapõe-se ao observado no município de Bragança, que vem acumulando uma série de problemas de ordem ambiental, social e econômica em decorrência do turismo.

Entendendo-se a importância estratégica do Polo Turístico Amazônia Atlântica e do seu potencial ecológico, este trabalho teve como objetivo discutir a relação entre as práticas de turismo desenvolvidas no município de Bragança e a demanda por ações de educação ambiental como instrumento de construção de uma gestão participativa do turismo local.

\section{Principais fatores que qualificam a atividade de turismo na Região Bragantina}

Bragança possui uma diversidade de atrativos naturais e culturais. De acordo com o Inventário Cultural de Bragança, desenvolvido pela Fundação Hilário Ferreira, em 2010, 
além de um conjunto arquitetônico, que a diferencia das cidades do nordeste paraense, o município possui também praias, mangues, campos e igarapés. Bragança ainda oferece iguarias aos visitantes, como caranguejo, sururu, peixes diversos, camarão, ostras e frutas regionais. Uma das referências mais antigas de Bragança se relaciona com a cultura agrícola da mandioca, cujo principal produto é a farinha, conhecida por sua qualidade e sabor.

As atividades econômicas mais expressivas na estrutura produtiva do município de Bragança estão ligadas ao setor primário, com ênfase à pesca, à agricultura e ao extrativismo. Além dessas, há a atividade Turística, ligada ao setor terciário da economia.

Atualmente, o turismo encontra-se entre as quatro principais atividades econômicas do mundo (OLIVEIRA, 2007) e, acompanhando esse crescimento, o município vem caminhando gradativamente para a conquista de uma boa infraestrutura turística, percebida no desenvolvimento urbano, por meio da implementação de espaços de eventos e de novos pontos turísticos, como o Mirante de São Benedito, além da expansão do setor de serviços, principalmente na hotelaria e na gastronomia.

Bragança, segundo a PARATUR, alcançou uma pontuação superior a 70 pontos no documento que classifica os municípios por meio de itens vinculados a aspectos da gestão do turismo e à organização do trade turístico, ficando, assim, no nível mais elevado. A classificação ocorre hierarquicamente em: Município Turístico (nível mais alto), Município com Potencial Turístico e Município de Apoio ao Turismo.

Alguns dos critérios que elevaram Bragança a esta classificação podem ser observados na estrutura de lazer, apoio, serviços e equipamentos turísticos do município, contidos no Quadro 1.

Em relação à demanda, o fluxo de turistas em Bragança ocorre de forma sazonal, com ápice nos meses de fevereiro, julho e dezembro, quando ocorre o carnaval, o verão bragantino e a festividade de São Benedito, respectivamente. $O$ culto à tradicional Marujada e a São Benedito se constituem em importantes manifestações, cultural e religiosa, da Amazônia paraense. São mais de 200 anos de história (SILVA, 2006).

O potencial turístico atende a diversos segmentos: Ecoturismo, Turismo de Sol e Praia, Turismo Religioso e Turismo Histórico-Cultural; seus atrativos possibilitam aos visitantes lazer e satisfação todos os meses, e o fluxo de turistas no município chega aos milhares a cada ano.

A praia oceânica de Ajuruteua, que começou a ser explorada principalmente a partir da construção, em 1983, da PA-458, e que fica distante 36 quilômetros da sede municipal, representa um dos principais encantos turísticos de Bragança. Até o início da década de 1980, essa praia encontrava-se praticamente inabitada, segundo Pereira et al. (2006b).

Além da praia, o município também está rodeado por balneários de água doce que oferecem serviços básicos de alimentação e alguns promovem festas dançantes para atrair um público maior e mais diversificado. Contudo, existem opções aos que procuram um ambiente reservado e calmo, prezando pela tranquilidade. 
Silva, G.V.; Pontes, A.N.; Pereira, A.M.; Lima, A.M.M.

Quadro 1: Informações com base na pesquisa de demanda hoteleira realizada em 2011 pela Secretaria Municipal de Turismo de Bragança.

Frame 1: Information based on research of hotel demand in 2011 conducted by the Department of Municipal Secretary of Tourism of Bragança.

\begin{tabular}{|c|c|c|c|}
\hline \multirow{2}{*}{ Unidades } & \multirow{2}{*}{ Categorias } & \multicolumn{2}{|c|}{ Sistema de Hospedagem } \\
\hline & & Itens & Quantidade \\
\hline \multirow{4}{*}{$\begin{array}{l}\text { Sede de } \\
\text { Bragança }\end{array}$} & \multirow{4}{*}{ Hospedagem } & Hotéis & 10 \\
\hline & & Pousadas & 02 \\
\hline & & Dormitório & 01 \\
\hline & & Motéis & 03 \\
\hline \multirow{20}{*}{ Ajuruteua } & Hospedagem & Pousadas & 23 \\
\hline & \multirow{3}{*}{$\begin{array}{l}\text { Serviços de alimen- } \\
\text { tos }\end{array}$} & Restaurante & 17 \\
\hline & & Pizzarias & 04 \\
\hline & & Restaurante/Ajuruteua & 11 \\
\hline & \multirow{5}{*}{$\begin{array}{l}\text { Serviços e equipa- } \\
\text { mentos de agencia- } \\
\text { mento }\end{array}$} & Agências de Turismo & 01 \\
\hline & & Transporte interurbano & 01 \\
\hline & & Transporte zona rural & 07 \\
\hline & & Transporte zona urbana & 02 \\
\hline & & Transporte Ajuruteua & 01 \\
\hline & \multirow{3}{*}{$\begin{array}{l}\text { Serviços e equipa- } \\
\text { mentos para eventos }\end{array}$} & Espaços culturais & 01 \\
\hline & & $\begin{array}{c}\text { Empresas de organização e promoção } \\
\text { de eventos }\end{array}$ & 02 \\
\hline & & Auditórios e salões de convenções & 12 \\
\hline & \multirow{8}{*}{$\begin{array}{l}\text { Serviços e equipa- } \\
\text { mentos de lazer e } \\
\text { entretenimento }\end{array}$} & Balneários & 08 \\
\hline & & Praças & 10 \\
\hline & & Clubes & 01 \\
\hline & & Academias & 03 \\
\hline & & Estádios/Ginásios/Quadras & 09 \\
\hline & & Mirantes & 02 \\
\hline & & Prestadores de serviço e entretenimento & 01 \\
\hline & & Casas de espetáculo & 04 \\
\hline
\end{tabular}

Fonte: Secretaria Municipal de Turismo de Bragança, PA, 2012.

Source: Bragança's Municipal Secretary of Tourism, PA, 2012. 
O município de Bragança possui ainda duas Unidades de Conservação da Natureza (SNUC - Lei 9.985/2000): Ilha do Canela (APA - Municipal), instituída pela Lei № 3.280/97; e Reserva Extrativista Marinha Caeté-Taperaçu (RESEX - Federal), criada pelo Decreto n. 4.340/02.

Com tantos atrativos, fomentar a atividade turística de forma sustentável por meio da inserção social contribuirá para a consolidação de Bragança como um destino turístico com potencial regional, mediante um desenvolvimento competitivo da atividade.

\section{Aspectos socioambientais associados ao turismo}

Um dos grandes problemas socioambientais na região bragantina atinge as áreas litorâneas. Segundo Guerra et al. (2005), a expressão impacto socioambiental é entendida como um desequilíbrio ambiental e social ocasionado por uma influência antrópica, acarretando uma relação desequilibrada entre homem/natureza.

O município de Bragança apresenta áreas litorâneas com uma riqueza significativa de recursos naturais, com potencial turístico em expansão. Porém, os parcos investimentos em infraestrutura na região têm afetado o ambiente natural local. Silva et al. (2009) consideram que a maioria das construções, feitas sobre ou próximo à linha da costa, alteram o delicado equilíbrio entre o suprimento de sedimentos e o poder erosivo das ondas, reduzindo assim a flexibilidade natural da praia. A intensa ocupação desordenada por residências, meios de hospedagens, bares e restaurantes, na área praiana de Bragança, vem colocando em risco seu ecossistema costeiro.

Os ambientes costeiros na área do município sofrem constantes modificações naturais. Holzer et al. (2004) afirmam que as zonas costeiras são constantemente afetadas por processos naturais de deposição marinha (ação eólica e marinha) e de drenagem fluvial.

Em Bragança é possível observar a redução das áreas de floresta de mangues (PEREIRA et al., 2006a), que passam a compor uma paisagem com aspecto de "degradação", marcada pela perda das características naturais, com a transformação para uma nova categoria de ambiente. Um exemplo dessa situação foi a implantação da estrada que liga a sede do município à zona costeira.

Até o final da década de 70, a falta de acesso às praias da planície costeira bragantina era vista como um obstáculo ao desenvolvimento do turismo na região (SILVA et al., 2009). A construção da estrada impulsionou o turismo e facilitou o deslocamento e a comunicação dos pescadores locais com a sede do município e outras regiões do estado. Todavia, as consequências ambientais são observadas atualmente por todos os turistas que frequentam a área.

Esse corredor foi instalado sobre extensas áreas ocupadas por mangues, ocasionando uma transformação na paisagem. As perdas são sentidas pelas comunidades locais, especialmente aquelas dependentes do extrativismo do mangue.

O alto nível de vulnerabilidade dos ecossistemas costeiros deve ser levado em consideração pelos gestores que primam pelo desenvolvimento de seus municípios. Isso porque esses ecossistemas, muitas vezes, não comportam certas atividades, como o tráfego excessivo de veículos, instalações e infraestrutura inadequadas à paisagem local. 
Um problema presente e que afeta diretamente a atividade turística na região é o tratamento dado aos resíduos sólidos nas áreas costeiras, principalmente nas praias. A gestão pouco eficiente dos resíduos sólidos gera um duplo impacto nas áreas em questão: o primeiro refere-se ao impacto econômico pelo distanciamento dos turistas, visto que estes são atraídos pela beleza local e a presença de resíduos sólidos espalhados pelas praias altera a paisagem, comprometendo sua beleza. Já o segundo impacto é justamente a alteração da paisagem local.

Ao longo da zona costeira bragantina não foi observado nenhum sistema de coleta de lixo, sendo este depositado regularmente nos campos de dunas. Seu impacto varia desde a poluição da linha de costa até influências na saúde da população, além de problemas estéticos e econômicos que abalam o turismo da área.

\section{Metodologia}

A relação entre as práticas de turismo desenvolvidas no município de Bragança e a demanda por ações de educação ambiental, tendo como enfoque a gestão social participativa, foi construída a partir de etapas que associam as pesquisas de campo e documental. Como ferramenta analítica, foi empregado o modelo DPSIR (Driving Forces - Pressures State - Impact - Responses) de análise de variáveis e identificação de relações voltadas à qualidade ambiental (BIDONE; LACERDA, 2004; SVARSTAD et al., 2008; BELL, 2012; TSCHERNING et al., 2012).

Os trabalhos de campo tiveram como objetivo mapear as áreas de atividades turísticas, compreender a relação das populações locais com os empreendimentos turisticos implantados e analisar a forma de organização dessas populações para enfrentar os conflitos ali estabelecidos.

A abordagem teórico-metodológica desta pesquisa é de natureza exploratória e descritiva, realizada a partir da pesquisa qualitativa (ALVES, 2011). Para Sampieri et al. (1994), o uso da pesquisa exploratória é pertinente quando o foco é examinar uma temática com pouco ou nenhum estudo anterior, o que permite uma aproximação que favorece a familiarização com os fenômenos envolvidos no estudo. Sendo assim, os trabalhos descritivos procuram apresentar e identificar características de um fenômeno, população ou situação.

Pesquisa qualitativa é entendida como multi metodológica no que diz respeito ao seu objetivo, envolve abordagens interpretativas e naturalísticas dos fenômenos (ALVES, 2011). Denzin e Lincoln (1994) afirmam que o pesquisador, ao optar pela pesquisa qualitativa, se debruça sob os fenômenos em seu ambiente natural, com a finalidade de dar sentido ou interpretar os fenômenos, segundo o significado que as pessoas Ihes atribuem.

A etapa analítica buscou no modelo DPSIR um mecanismo para análise da relação turismo versus qualidade ambiental. Para tanto, de acordo com Borja et al. (2005), as Forças Motoras (Driving Forces) são normalmente consideradas como sendo políticas, econômicas e sociais dos governos; as Pressões (Pressures) são os caminhos em que esses elementos condutores são expressos e o modo como os ecossistemas e seus componentes são perturbados; essas pressões afetam o Estado (State) do ambiente, impactam (Impact) na saúde humana e nos ecossistemas, obrigando a formulação de Respostas (Responses). Estas últimas dar-se-ão por meio de várias medidas de política, tais como regulamentos, informações, impostos e planos diretores municipais. 


\section{Resultados}

\section{O processo de planejamento e gestão participativa do ecoturismo: análise empregan- do o modelo DPSIR}

O cenário identificado no município Bragança indica que o processo de participação efetiva da comunidade, de gestores, empreendedores e das associações no processo de gestão e desenvolvimento local é fundamental para a construção de uma perspectiva harmônica entre a atividade econômica e a natureza.

\section{1) Avaliação segundo os impactos sob os sistemas naturais locais}

O primeiro ponto de destaque é a questão do atrativo natural que a região apresenta. Essa força motora impulsiona as pessoas a explorarem ao máximo diferentes regiões. Entretanto, todas as vezes que algo novo "é descoberto", existe o apelo para que seja implantada a infraestrutura de apoio para facilitar a permanência do turista neste local (Figura 2).

\begin{tabular}{|c|c|}
\hline Variàvel & - Vulnerabilidade natural dos ecossistemas costeiros. \\
\hline $\begin{array}{l}\text { Forcas } \\
\text { Motoras } \\
\text { (Driving } \\
\text { Forces) }\end{array}$ & - Diversidade de atrativos naturais e culturais. \\
\hline $\begin{array}{l}\text { Pressöes } \\
\text { (Presșureș) }\end{array}$ & - Exploração do potencial. \\
\hline $\begin{array}{l}\text { Estado } \\
\text { (State) }\end{array}$ & $\begin{array}{l}\text { - Ambientes preservados com indicios de antropismo: desmate, resicuos sólidos e } \\
\text { prática do extrativismo predatorio da fauna local. }\end{array}$ \\
\hline $\begin{array}{l}\text { Impactos } \\
\text { (Impact) }\end{array}$ & $\begin{array}{l}\text { - Tráfego excessivo de veiculos. Instalaçóes e infraestrutura inadequadas à paisagem } \\
\text { do local. Falta de coleta e tratamento de ésgoto. Nắo rétirada de résiduos sólidos. } \\
\text { Poluição sonora e do ar. Redução do número de individuos naturais dos ambientes } \\
\text { de manguezais pela sua constante retirada. }\end{array}$ \\
\hline $\begin{array}{l}\text { Respostas } \\
\text { (Responses) }\end{array}$ & $\begin{array}{l}\text { - Gestáo ambiental municipal focada na promoçắ da estruturaçăo de um sistema } \\
\text { municipal de planejamento e gestäo urbana, democratizado, descentralizado, } \\
\text { integrado, permanente e continuo; no planejamento do espaço urbano e na } \\
\text { preservaçäo de ambientes protegidos, considerando os aspectos de saneamento, } \\
\text { controle do avanço imobiliario, manutença de areas verdes (Areas de Preservação } \\
\text { Permanente) e açóses educativas continuadas para o desenvolvimento do } \\
\text { ecoturismo. }\end{array}$ \\
\hline
\end{tabular}

Figura 2: Análise pelo modelo DPSIR das variáveis: avanço do turismo em áreas de vulnerabilidade, perda de biodiversidade a partir do processo de ocupação do seu entorno e constante visitação por parte dos turistas.

Figure 2: Analysis by DPSIR model of the variables: tourism advancement in areas of vulnerability, loss of biodiversity due to the progress of occupation and constant visitation by tourists.

Observa-se que a atividade, quando executada em ambientes que representam áreas de maior sensibilidade ambiental (USHER, 2001), passa a incorporar o conceito 
de pegada ecológica (CORDEIRO et al., 2010a), por representar uma demanda humana sobre os ecossistemas naturais, devendo assim contabilizar as perdas/ganhos existentes e inseri-los nas relações econômicas locais.

Gregory et al. (2013) empregaram o modelo DPSIR para orientar o processo de extrativismo de fauna marinha (Flamborough Head, UK). Na sua formulação de análise, também foi utilizada a lógica de incorporação dos impactos gerados pela atividade como forma de controle de sua expansão, destacando o envolvimento social e a avaliação da capacidade de suporte dos ecossistemas alterados como forma de Resposta.

Propõe-se, portanto, como Resposta, para o município de Bragança, que a gestão ambiental municipal incorpore, por meio de ações de controle e fiscalização junto aos investidores, as intervenções na fauna e flora locais, e na regulação do avanço imobiliário e comercial; de forma que os serviços básicos vinculados ao saneamento (esgotamento sanitário e coleta de lixo), abastecimento de água e fornecimento de energia se tornem mais "caros", por incorporarem os "impactos" gerados pela intervenção humana na faixa litorânea e nos manguezais. O desenvolvimento de ações de educação ambiental continuada visaria apoiar o reconhecimento social deste diferencial, para evitar sua rejeição por parte dos comerciantes e turistas que considerem "desnecessária" a incorporação do custo ambiental.

Cordeiro et al. (2010b) aplicam o Método da Pegada Ecológica do Turismo como uma ferramenta útil para avaliar a sustentabilidade de um destino turístico, na Região Autônoma dos Açores (Portugal). Considerando os pressupostos definidos por Gössling et al. (2002), que entende que devem ser agregados à atividade os consumos/resíduos compreendidos a partir de quatro categorias: transportes; acomodação; atividades; alimentação e consumo. Porém, para que esta proposta tenha uma boa receptividade, ela não pode ser entendida como um entrave para o desenvolvimento local pela população, disso advém a necessidade da participação social no processo de tomada de decisão.

O art. $4^{\circ}$ da Lei n‥ 3.875/06 (que dispõe sobre o Plano Diretor Municipal Participativo de Bragança) prevê a promoção da estruturação de um sistema municipal de planejamento e gestão urbana, democratizado, descentralizado, integrado, permanente e contínuo. A gestão democrática dar-se-á por meio da participação popular e da democratização das relações entre sociedade civil e o estado.

A gestão participativa e descentralizada é prevista tanto nas políticas ambientais (federal - Lei n. 6.938/1981; estadual - Lei n. 5.887/1995; municipal - Lei n. 4.035/2009) quanto na Política Nacional de Recursos Hídricos (Lei n. 9433/2007), além da estadual (Lei n. 6381/2001). Os debates sobre as questões do meio ambiente direcionam para que as atividades produtivas devam se desenvolver sob princípios ecológicos básicos, exigindo um componente social que incorpore esta limitação (MADRUGA et al., 2011). Dessa forma, é reconhecido que o equilíbrio entre a necessidade de desenvolvimento econômico municipal e o uso sustentável dos recursos naturais representa um desafio. 


\section{2) Desenvolvimento local (emprego e renda) e qualidade ambiental}

Para Fernández e Rivero (2009), crescimento econômico, qualidade de vida e qualidade ambiental devem estar em um mesmo patamar. Já os modelos de governança locais devem estar associados à internalização dos custos ambientais, à justiça social e ao desenvolvimento de um modelo econômico compatível com uma proposta sustentável. Isso conduz à ideia da importância da gestão social participativa vinculada ao ordenamento territorial em áreas de potencial para o ecoturismo. Disso advém o segundo ponto de análise, que relaciona o desenvolvimento local a um processo participativo e atuante na manutenção da qualidade ambiental dos sistemas naturais existentes (Figura 3).

\begin{tabular}{|c|c|}
\hline Variável & - Desenvolvimento econômico municipal, geração de trabalho e renda. \\
\hline $\begin{array}{l}\text { Forças } \\
\text { Motoras } \\
\text { (Driving } \\
\text { Forces) }\end{array}$ & - Implantação de um setor produtivo de suporte ao ecoturismo. \\
\hline $\begin{array}{l}\text { Pressóes } \\
\text { (Pressures) }\end{array}$ & - Crescimento sem considerar a capacidade de suporte local. \\
\hline $\begin{array}{l}\text { Estado } \\
\text { (State) }\end{array}$ & $\begin{array}{l}\text { - Concentraçăo de atividades em uma unica regiăo e sua expansăo sobré ambientes } \\
\text { destinados a preservação. }\end{array}$ \\
\hline $\begin{array}{l}\text { Impactos } \\
\text { (Impact) }\end{array}$ & $\begin{array}{l}\text { - Exploração dos recursos naturais e ampliação das consequências do antropismo } \\
\text { com a geração de poluiçắo e contaminaçăo ambiental. }\end{array}$ \\
\hline $\begin{array}{l}\text { Respostas } \\
\text { (Responses) }\end{array}$ & $\begin{array}{l}\text { - Gestão ambiental municipal e estadual atuante na formulaçäo de politicas e } \\
\text { implantaça de projetos voltados a preservaça de ambientes destinados a } \\
\text { proteção integral, incluindo o envolvimento social e do setor produtivo. Definiçăo de } \\
\text { uma politica de incentivos para o estimulo do ecoturismo e de atividades produtivas } \\
\text { vinculadas a este. }\end{array}$ \\
\hline
\end{tabular}

Figura 3: Análise pelo modelo DPSIR das variáveis: desenvolvimento econômico municipal, geração de trabalho e renda.

Figure 3: Analysis by DPSIR model of the variables: municipal economic development, employment and income generation.

Nesse caso, a qualidade ambiental está relacionada à capacidade de suporte do município (Figura 4). A questão do turismo de massa é bem atrativa na perspectiva econômica, pois gera uma renda ao setor produtivo local que equivale ao resto do ano de trabalho. Porém, as consequências desse setor são muito fortes, e confrontam 
com aquilo que se espera de um turismo sustentável baseado na lógica de que (SACHS, 2001):

- O ambiente é a principal fonte de matéria prima dos atrativos;

- O social (a comunidade receptora, o patrimônio histórico-cultural e a interação com os visitantes) demanda por um padrão de qualidade;

- O econômico (com todos os inter-relacionamentos e interdependências da cadeia produtiva) permite a articulação com as unidades de produção e de negócios viáveis identificadas nas comunidades, atuando de forma integrada, proativa e interativa, buscando incrementar a produtividade para o alcance de competitividade;

- O político se instrumentaliza mediante estratégias de gestão que possibilitem coordenar as iniciativas locais na criação de um entorno emulativo de produção, favorecendo o desenvolvimento sustentável.

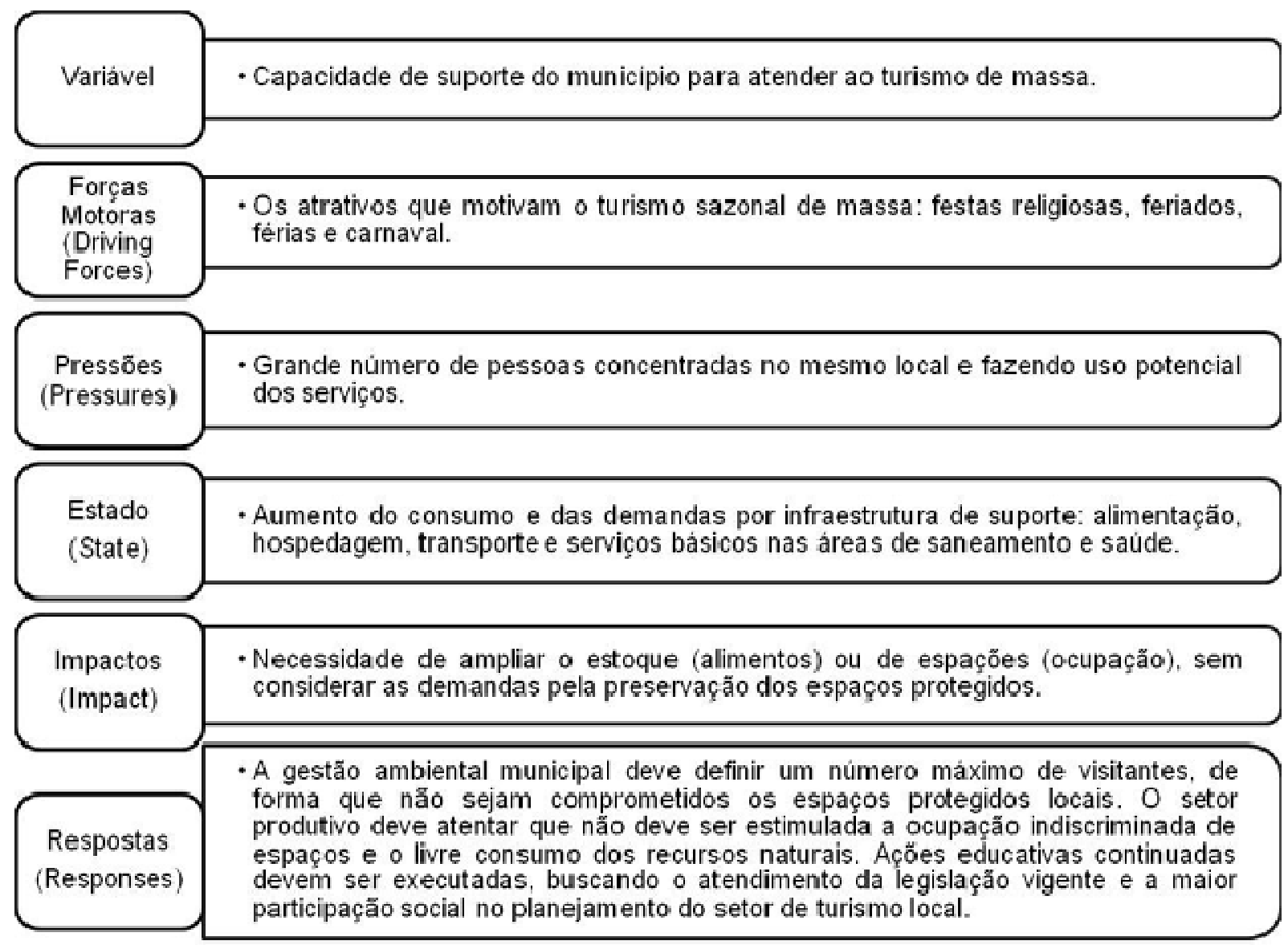

Figura 4: Análise pelo modelo DPSIR da variável: capacidade de suporte do município para a atividade de turismo.

Figura 4: Analysis by DPSIR model of the variable: carrying capacity of the municipality for tourism activity. 
Analisar a demanda econômica de desenvolvimento local e a capacidade de suporte, considerando as limitações que a infraestrutura municipal oferece e as restrições ambientais (legais), impõem Respostas embasadas na atuação conjunta entre a administração pública, o setor produtivo e a sociedade, que busca em Bragança um ambiente de lazer e de apreciação paisagística. Nesse sentido, destaca-se a Lei $\mathrm{n}$. 7.661/1988, que dispõe sobre o Plano Nacional de Gerenciamento Costeiro (PNGC), sua Revisão (PNGC II), de 1997, e o Decreto n. 5.300/2004, que regulamenta o uso e ocupação da zona costeira e fornece critérios de gestão da orla marítima.

Essas normas destacam a execução da gestão costeira em conformidade com o princípio da descentralização, assegurando o comprometimento e a cooperação entre os níveis de governo, e desses com a sociedade, no estabelecimento de políticas, planos e programas estaduais e municipais; tendo como um de seus instrumentos o Plano Municipal de Gerenciamento Costeiro (PMGC), que deve guardar estreita relação com os planos de uso e ocupação territorial e outros pertinentes ao planejamento municipal.

Para Atkins et al. (2011), o gerenciamento de ambiente costeiro deve envolver os setores associados aos produtos obtidos a partir dos ecossistemas locais, a regulamentação dos serviços ambientais e a incorporação dos serviços culturais.

Um exemplo de proposta que agrega emprego e renda com sustentabilidade é associada ao Turismo de Base Comunitária, que implica na participação da comunidade no planejamento e gestão do turismo, na conservação dos recursos naturais e/ ou culturais, no desenvolvimento econômico e social, na geração de benefícios econômicos e sociais para a comunidade local, na qualidade e na experiência do visitante, comprometido com a responsabilidade social e ambiental (FABRINO et al., 2012).

O município de Bragança incorpora tanto a oferta de serviços ambientais quanto culturais, por isso as Respostas definidas devem incorporar a sociedade no processo de tomada de decisões. Nessa proposta, a educação ambiental pode ser considerada como uma ação mediadora desse "feedback social", junto às políticas e/ou ações de planejamento envolvendo ações de controle ou mitigação, principalmente em função da pressão social pela garantia de emprego e renda para a população local (NESS, 2010).

\section{Discussão}

\section{A educação ambiental e o ecoturismo no município de Bragança: proposta de uma gestão partilhada}

Promover o ecoturismo em Bragança é uma exigência vocacional da região, que possui uma variedade de atrativos naturais e culturais. Todavia, é necessário compatibilizar o desenvolvimento econômico, a conservação dos recursos utilizados e a sustentabilidade socioambiental. Para Hanai et al. (2011, p.7), o desafio da sustentabilidade em destinos turísticos é urgente e requer o compromisso institucional das autoridades locais, assim como a colaboração ativa dos atores individuais que atuam nos destinos. 
Para que o ecoturismo possa ser desenvolvido respeitando a natureza, a cultura local e a participação da comunidade na tomada de decisões, assim como contribuir para que o turista tenha uma experiência rica e agradável, é indispensável investir no planejamento de atividades que compreendam os interesses coletivos.

Em Bragança, de forma geral, o turismo está entre as atividades econômicas mais expressivas na estrutura produtiva do município, pois sua contribuição estimula a melhoria da qualidade de vida da comunidade, uma vez que esta atividade abrange múltiplos componentes associados a outros setores da economia, no âmbito formal e informal (OLIVEIRA, 2007).

Além dos atrativos da zona costeira, trata-se de uma cidade histórica (a cidade de Bragança foi criada em 1854), que tem como maior manifestação de cunho cultural a Marujada, que se apresenta por ocasião da Festa de São Benedito. Logo, ao fomentar a atividade turística de forma sustentável, cria-se uma referência que ultrapassa seu sentido mercadológico, pois torna-se um segmento do turismo que estreita as relações de ações coletivas.

Para a mitigação dos problemas ambientais causados pelo fenômeno turístico e para o equilíbrio entre a necessidade de desenvolvimento econômico municipal e o uso sustentável dos recursos naturais, faz-se necessário atuar de forma continuada com ações de regulação que administrem tais impactos, sendo necessária a definição das relações de causa e efeito (QUARESMA; CAMPOS, 2006; PINTO, 2007).

A estrutura metodológica aplicada a esta pesquisa revelou alguns problemas identificados em sua área de abrangência, entre eles a perda de biodiversidade, consequência da ocupação desordenada do seu entorno e do aumento do fluxo de turistas, que exercem pressões diretas no ambiente, afetando as condições de vida da população com a intensa exploração de seu potencial e seus recursos, indicando a educação ambiental, associada à gestão ambiental pública, como resposta no sentido de mitigar tais inconformidades.

O método DPSIR, empregado neste estudo, considera que as atividades econômicas influenciam nos impactos ambientais (FERNANDES et al., 2011). Tal método permitiu considerar o desenvolvimento econômico municipal, a geração de trabalho e renda e a capacidade de suporte do município para a atividade de turismo como variáveis que apontam indicadores que induzem dimensões positivas, como o crescimento e a dinamização dos setores econômicos locais; e negativas, como a exploração dos recursos naturais, as desigualdades sociais e a perda da qualidade ambiental.

A avaliação por meio do DPSIR tem sido adotada com finalidades diversas, mas sempre voltadas a uma proposta de sistema de suporte a decisão para definição de ações e/ou políticas voltadas à minimização de impactos gerados pelas atividades humanas: Jago-on et al. (2008) aplicaram esse método em sete cidades metropolitanas asiáticas, focando nos problemas decorrentes da urbanização; Fernández e Rivero (2009) usaram o método para compor um índice aplicado ao turismo de base sustentável para 17 regiões na Espanha; Naviglio et al. (2009) avaliaram o método e suas aplicações voltadas à gestão e planejamento ambiental na Itália; Lončar (2010) o apli- 
ca à llha de Murter (Croácia), na identificação de ações que potencializem o desenvolvimento social e econômico, compatível com o ambiental, dentre estas as voltadas ao turismo; Fernandes e Barbosa (2011) formularam indicadores socioeconômicos e ambientais empregando o método, tendo como foco de análise o processo de desertificação em quatro municípios no Brasil (Araripina e Marcolândia/PI; Crato e Barbalha/CE).

A educação ambiental é uma "Resposta" sempre presente quando se analisa a sustentabilidade do setor de turismo, pois aparece como uma interlocução entre a comunidade e o poder público. Severino e Tomasulo (2012), em um estudo realizado em Santa Catariana, observaram que a participação dos moradores no turismo local atingiu $50 \%$ do percentual levantado. Para esses autores, a porcentagem confirma que o planejamento participativo e integrado pode ser uma realidade nos destinos turísticos; logo, se estruturado e articulado com ações continuadas, pode representar resultados positivos e continuados para a atividade.

Faz-se necessário, portanto, investir no planejamento de atividades que envolvam os atores da cadeia produtiva dessa atividade em sua dinamicidade (MAXIMIANO, 2007).

O planejamento participativo se firma em um processo democrático, fundamentado em mecanismos de participação direta, envolvendo as representações dos atores envolvidos (PAIVA, 2010). Esse processo, dentro do planejamento turístico, permite ampliar os questionamentos e a compreensão acerca dos problemas locais e ainda articular soluções que atendam ao interesse coletivo, por meio de um consenso social (KOGA et al., 2013).

Desenvolver o turismo sustentável e participativo demanda: valorizar o potencial turístico local; permitir o usufruto dos atrativos ambientais, culturais, patrimoniais e paisagísticos; assegurar à comunidade representatividade expressiva, com direito a voto nos conselhos deliberativos e consultar a comunidade previamente sobre a viabilidade ou não da implantação de qualquer atividade (RODRIGUES, 2009).

A partir das análises feitas, propõe-se o desenvolvimento de um Programa de Educação Ambiental com o objetivo de responder às demandas identificadas, relacionadas aos problemas ambientais. Enquanto ferramenta no processo de gestão participativa, a educação ambiental estenderá o uso da informação para expor ao turista o quanto determinado sistema é vulnerável, além de definir limites, à medida que se difunde uma consciência ecológica, por meio do estímulo à percepção coletiva sobre o meio ambiente e se desenvolvem habilidades de argumentação em defesa do interesse ambiental e social local (CARVALHO; COSTA, 2013).

\section{Considerações finais}

Os resultados apontados por meio do Modelo DPSIR indicaram algumas pressões exercidas sobre os recursos naturais, provenientes da atividade turística na região bragantina.

O turismo, durante muito tempo, foi considerado uma fonte de economia limpa (ou de forma mais apropriada atualmente - Economia Verde). Todavia, os impactos surgem no desenvolvimento da infraestrutura para a atividade turística por meio, por 
exemplo, de processos conhecidos como input (entrada), que diz respeito ao uso dos recursos naturais, e como output (saída), referente ao consumo e/ou geração de produtos que levam a formas de impactos poluidoras. $O$ estado do ambiente, registrado no método DPSIR, indica um alerta para os impactos e as transformações que desencadeiam problemas socioambientais em Bragança. A educação ambiental, sob a forma de ações no planejamento e na gestão social e participativa, é proposta como uma das ações inseridas no escopo de "Resposta" para esses problemas.

A atividade turística destaca-se na economia do município de Bragança. O turismo impulsiona a geração de emprego e renda para a comunidade e mobiliza outros setores que contribuem para o desenvolvimento local. O capital circulado durante o período em que o fluxo de visitantes é maior anima empreendedores e trabalhadores do setor informal que também se beneficiam com a renda. Os investimentos têm crescido e atraído novos recursos e serviços. Contudo, essa movimentação também tem trazido problemas socioambientais e culturais.

Empreender o ecoturismo em Bragança (associado ao turismo de base comunitária) permitiria a abertura de novos empreendimentos socioambientais dentro da prática do turismo, e de novos negócios sustentáveis envolvidos na cadeia dessa atividade econômica.

O município de Bragança, portanto, demanda por ações e políticas públicas que integrem, na administração municipal e estadual, ações de regulação, fiscalização e monitoramento à capacidade de suporte dos recursos naturais existentes. Nessa relação, a educação ambiental atuaria como uma forma de garantir o diálogo social, para maior internalização das ações e sua efetividade ao longo do tempo, tendo como focos a compreensão dos impactos do turismo sobre o meio natural, cultural e humano, a distribuição justa dos benefícios e custos, e a diversificação da economia local.

\section{Referências bibliográficas}

AGUIAR, P.W.; PADUA, S.M.; GOMES, M.A.O.; UEZU, A. Subsídios para o planejamento de trilha no Parque Estadual da Serra Furada (SC). Revista Brasileira de Ecoturismo, São Paulo, v. 3, n. 3, p. 498-527, 2010.

ALVES, M.L.B. Reflexões Sobre a Pesquisa Qualitativa Aplicada ao Turismo. Turismo em Análise, v. 22, n. 3, p. 459-613, 2011.

ATKINS, J.P.; BURDON, D.; ELLIOTT, M.; GREGORY, A.J. Management of the marine environment: Integrating ecosystem services and societal benefits with the DPSIR framework in a systems approach. Marine Pollution Bulletin, n. 62, p. 215-226, 2011.

BELL, S. DPSIR = A Problem Structuring Method? An exploration from the "Imagine" approach. European Journal of Operational Research, n. 222, p. 350-360, 2012.

BIDONE, E.D.; LACERDA, L.D. The use of DPSIR framework to evaluate sustainability in coastal areas. Case study: Guanabara Bay basin, Rio de Janeiro, Brazil. Reg. Environmental Change, 4:5-16, 2004. 
Contribuições da Educação Ambiental para o turismo em Bragança (PA) (Amazônia Atlântica): uma perspectiva participativa

BORJA, A.; GALPARSORO, I.; SOLAUN, O.; MUXIKA, I.; TELLO E M.; URIARTE, A.; VALENCIA, V. The European Water Framework Directive and the DPSIR, a methodological approach to assess the risk of failing to achieve good ecological status. Estuarine, Coastal and Shelf Science, n. 66, p. 84-96, 2006.

BRASIL, Lei no 1.806, de 6 de janeiro de 1953. Dispões sobre o plano de valorização econômica da Amazônia, cria a superintendência da sua execução e o conceito de Amazônia Legal. Diário Oficial da república Federativa do Brasil, Rio de janeiro, DF, 7 de jan. 1953. Disponível em: http://legis.senado.gov.br/sicon/index.jsp. Acesso em: 12 dez. 2012.

BRASIL. Decreto 4.340, de 22 de agosto de 2002. Dispõe sobre o Sistema Nacional De Unidades ee Conservação da natureza- SNUC, e da outras providencias. Disponível em: http://legis.senado.gov.br/sicon/index.jsp. Acesso em: 10 de jan. 2013.

CACHO, A.N.B.; AZEVEDO, F.F. O turismo no contexto da sociedade informacional. Revista Brasileira de Pesquisa em Turismo, v. 4, n. 2, p. 31-48, 2010.

CARVALHO, A.; AZEITEIRO, U.M.; MEIRA-CARTEA, P. Equipamentos para a Educação Ambiental na zona costeira da Euroregião do Eixo Atlântico: das práticas conservacionistas às sociocríticas. Revista de Gestão Costeira Integrada, 11(4): 433-450, 2011.

CARVALHO, B.C.; COSTA, V.C. Educação Ambiental na visão ecoturística: turismo e desenvolvimento local no município de Rio das Ostras (RJ). Revista Brasileira de Ecoturismo, São Paulo, v. 6, n. 1, p. 171-190, 2013.

CORDEIRO, I.D.; KÖRÖSSY, N.; PARTIDÁRIO, M.R. Instrumentos de avaliação de sustentabilidade de destinos turísticos: uma revisão de literatura. Caderno Virtual de Turismo, v. 10, n. 2, p. 49-64, 2010.

CORDEIRO, I. D.; KÖRÖSSY, N.; PARTIDÁRIO, M.R. The ecological footprint method for evaluating sustainable tourism: an case study of applied to the Azores Autonomous Region (Portugal). Revista Turismo Visão e Ação, v. 12, n. 3, p. 236-257, set-dez, 2010(b).

DENZIN, N.K.; LINCOLN, Y.S. Handbook of qualitative research. London: Sage Publication, 1994, $767 \mathrm{p}$.

ESPÍNOLA, R.S.; CASTRO, V.M. Ecoturismo e gestão participativa em Áreas Protegidas: o caso da Floresta Nacional do Tapajós (PA). Revista Brasileira de Ecoturismo, São Paulo, v. 5, n. 2, p. 281-296, 2012.

FABRINO, N.H.; COSTA, H. A.; NASCIMENTO, E.P. Turismo de Base Comunitária (TBC): elementos chaves para aferir seu desempenho na perspectiva da sustentabilidade. Revista Brasileira de Ecoturismo, São Paulo, v. 5, n. 3, p. 546-559, 2012.

FERNANDES, M.F.; BARBOSA, M.P. Aplicações dos Indicadores Socioeconômicos e Ambientais no Modelo DPSIR (Força Motriz/Pressão/Estado/Impacto/Resposta) e Influências na Desertificação nos Municipios de Araripina-PI, Crato e Barbalha-CE e Marcolândia-PI. Revista Brasileira de Geografia Física, v. 4, 722-737, 2011. 
FERNÁNDEZ, J.I.; RIVERO, M.S. Measuring tourism sustainability: proposal for a composite index. Tourism Economics, 15 (2), p. 277-296, 2009.

FORTUNATO, R.A. Representação social da educação ambiental e sua contribuição ao turismo. Revista Brasileira de Ecoturismo, São Paulo, v. 2, n. 2, p. 60-187, 2009. GÖSSLING, S.; HANSSON, C.B.; HÖRSTMEIER, O.; SAGGEL, S. Ecological footprint analysis as a tool to assess tourism sustainability. Ecological Economics, n. 43, p. 199-211, 2002.

GUERRA, A.J.T.; ALMEIDA, J.R.; ARAUJO, G.H.S. Gestão Ambiental de áreas degradadas. Rio de Janeiro. Editora Bertrand Brasil, 2005, 248 p.

GREGORY, A.J.; ATKINS, J.P.; BURDON, D.; ELLIOTT, M. A problem structuring method for ecosystem-based management: The DPSIR modelling process. European Journal of Operational Research, n. 227, p. 558-569, 2013.

HANAI, F.Y.; ESPINDOLA, E.L.G. Programa de Sensibilização Sustentável do Turismo: uma proposta para envolvimento e participação de comunidades locais. Turismo em Análise, v. 22, n. 1, p. 4-24, 2011.

HOLZER, W.; CRICHYNO, J.; PIRES, A.C. Sustentabilidade da urbanização em áreas de restinga: uma proposta de avaliação pós-ocupação. Paisagem Ambiente, $n$. 19, p. 49-65, 2004.

IGNARRA, L.R. Fundamentos do Turismo. São Paulo: Thomson Learning, 2003, $205 \mathrm{p}$.

JAGO-ON, K.A.B.; KANEKOB, S.; FUJIKURAC, R.; FUJIWARAB, A.; IMAID, T.; MATSUMOTOE, T.; ZHANGB, J.; TANIKAWAF, H.; TANAKAB, K.; LEEG, B.; TANIGU$\mathrm{CHIA}, \mathrm{M}$. Urbanization and subsurface environmental issues: An attempt at DPSIR model application in Asian cities. Science of the Total Environment, n. 407, p. 30893104, 2009.

KOGA, E.S.; OLIVEIRA, C.S.; KANESHIRO, D.M. Programa de capacitação do Projeto de Ecoturismo na Mata Atlântica no entorno dos parques estaduais paulistas. Revista Brasileira de Ecoturismo, São Paulo, v. 6, n. 1, p. 255-268, 2013.

LEAL-FILHO, W. A educação ambiental aplicada ao turismo: experiências da Costa de Caparica, Portugal. In: PEDRINI, A. G. Ecoturismo e Educação Ambiental. Rio de Janeiro: Publit, 2005. 25 p.

LEFF, E. (Org.). A complexidade ambiental. São Paulo: Cortez, 2003, 342 p.

LONČAR, N. The application of DPSIR model in analyzing the space and environmental state on Murter Island. Geoadria, 15/1, p. 49-80, 2010.

MADRUGA, L.R.G.; SILVA, T.N.; BEURON, T.; BLOCK, A. Comitê de Bacia: Uma Configuração Social Emergente na Gestão Sustentável das Águas. Desenvolvimento em Questão, v. 9, n. 18, p. 79-110, 2011.

MAXIMIANO, AC.A. Teoria Geral da Administração. São Paulo: Atlas, 2007, 521 p. 
Contribuições da Educação Ambiental para o turismo em Bragança (PA) (Amazônia Atlântica): uma perspectiva participativa

MÉSZÁROS, I. Para além do capital. Campinas, São Paulo: Boitempo, 2002, 1093 p.

NAVIGLIO, L.; CASTORINA, M.; BARBATO, F.; PACI, S.; SBRANA, M.; SIGNORINI, A. DPSIR: uno strumento di analisi ambientale applicabile a fini gestionali. Energia, Ambiente e Innovazione, n. 5, p. 85-96, 2009.

NECHAR, N.C. Epistemología crítica del turismo. Qué es eso? Turismo em Análise, v. 22, n. 3, p. 516-538, 2011.

NEIMAN, Z.; RABINOVICI, A. A educação ambiental através do ecoturismo: o diferencial das atividades de contato dirigido com a natureza. Pesquisa em Educação Ambiental, v. 3, n. 2, p. 77-101, 2008.

NESS, B.; ANDERBERG, S.; OLSSON, L. Structuring problems in sustainability science: The multi-level DPSIR framework. Geoforum, n. 41, p. 479-488, 2010.

OLIVEIRA, E.S. Impactos socioambientais e econômicos do turismo e as suas repercussões no desenvolvimento local: o caso do Município de Itacaré - Bahia. Revista Internacional de Desenvolvimento Local, v. 8, n. 2, p. 193-202, 2007.

PAIVA, M.G.M.V. Análise do Programa de Desenvolvimento do Turismo do Nordeste (PRODETUR/NE) na perspectiva do planejamento estratégico. Revista de Administração Pública. Rio de Janeiro 44(2): 197-213, 2010.

PARÁ. Plano de Desenvolvimento Turístico do Estado do Pará. Belém: PARATUR, 2001.

PEREIRA, A.P.F.G.; ANDRADE, F.A.G.; FERNANDES, M.E.B. Dois anos de monitoramento dos atropelamentos de mamíferos na rodovia PA-458, Bragança, Pará. Boletim do Museu Paraense Emilio Goeldi, Ciências Naturais, v. 1, n. 3, p. 77-83, 2006a.

PEREIRA, L.C.C; RIBEIRO, M.J.S; GUIMARÃES, D.O. ; SOUZA FILHO, P.W.M; COSTA, R.M. Formas de uso e ocupação na praia de Ajuruteua-Pará (Brasil). Desenvolvimento e Meio Ambiente, n. 13, p. 19-30, 2006b.

PINTO, P.M. Políticas de turismo e sustentabilidade em comunidades tradicionais: perspectivas conceituais. Bol. Mus. Para. Emílio Goeldi. Ciênc. hum., v. 2, n. 1, p. 11-22, 2007.

PLASTINO, M.R.; PEREIRA, D.C.; MAIA, M.G.M.; LOPES, D.A. Ecoturismo, cultura e comunidades: reflexões sobre o entorno da RPPN Santuário do Caraça (MG). Revista Brasileira de Ecoturismo, São Paulo, v. 3, n. 3, p. 382-407, 2010.

QUARESMA, H.D.A.B.; CAMPOS, R.I.R. Turismo como instrumento de ação coletiva em áreas pesqueiras do litoral da Amazônia. Bol. Mus. Para. Emílio Goeldi. Ciênc. hum. v. 1, n. 2, p. 139-147, 2006.

RABINOVICI, A. Organizações Não Governamentais, comunidades e turismo na Amazônia Brasileira: conflitos e sustentabilidade. In: Seminário Internacional Amazônia e Fronteiras do Conhecimento, 1, 2008, Belém. Anais IV ENANPPAS. Belém: UFPA, 2008.

RODRIGUES, J.M. Ecoturismo construindo a materialidade dos assentamentos: uma história de legitimação da terra no Distrito Federal - DF. Revista Brasileira de Ecoturismo, São Paulo, v. 2, n. 2, p. 118-141, 2009. 
Silva, G.V.; Pontes, A.N.; Pereira, A.M.; Lima, A.M.M.

RUSCHMANN, D. Turismo e planejamento Sustentável: a proteção do meio ambiente. Campinas: Papirus, 2001

SACHS, I. Caminhos para o desenvolvimento sustentável. Rio de Janeiro: Garamond, 2001, $95 \mathrm{p}$.

SAMPIERI, R.H.; COLLADO, C.F.; LUCIO, P.B. Metodología de la Investigación. México: McGraw Hill, 1994, 850 p.

SANDEVILLE JR, E.; SUGUIMOTO, F.T.; SILVA, C.E.L. Ecoturismo e (Des)Educação Ambiental. Revista Brasileira de Ecoturismo, São Paulo, v. 3, n. 1, p. 47-60, 2010.

SANTOS, R.B.N.; SANTANA, A.C. Comportamento recente do setor florestal madeireiro no estado do Pará, Brasil. Revista Árvore, Viçosa-MG, v. 33, n. 3, p. 533-543, 2009.

SEVERINO, S.; TOMASULO, S. Planos Estratégicos Municipais de Turismo do Estado de Santa Catarina - Roteiros Turísticos Regionais: um estudo. Turismo em Análise, v. 23, n. 2, p. 408-436, 2012.

SILVA, C.B. Educação ambiental para visitantes de unidades de conservação marinhas. Revista Brasileira de Ecoturismo, São Paulo, v. 4, n. 4, p. 509, 2011.

SILVA, D.B.R.N. Os Donos de São Benedito: convenções e rebeldias na luta entre o catolicismo tradicional e devocional na cultura de Bragança, século XX. 2006, $202 f$. Dissertação (Mestrado em História Social da Amazônia), IFCH/PPHIST. Universidade Federal do Pará, Belém: novembro, 2006.

SILVA, G.P.; NOGUEIRA, E.M.; PEREIRA, M.N.L. Promoção do turismo na Praia Grande (MA): entre a fantasia e a realidade no cenário do patrimônio cultural. Revista Brasileira de Ecoturismo, São Paulo, v. 5, n. 3, p. 530-545, 2012.

SILVA, I.R.; SOUZA FILHO, J.R.; BARBOSA, M.A.L.; REBOUÇAS, F.; MACHADO R.A.S. Diagnóstico ambiental e avaliação da capacidade de suporte das praias do bairro de Itapoã, Salvador, Bahia. Sociedade \& Natureza, Uberlândia, 21(1): 71-84, 2009.

SNUC. Sistema Nacional de Unidades de Conservação da Natureza. Lei n. 9.985, de 18 de julho de 2000. Brasília: MMA/SBF, 2000.

SOUSA, E.B.; COSTA, V.B.; PEREIRA, L.C.C.; COSTA, R.M. Microfitoplâncton de águas costeiras amazônicas: Ilha Canela (Bragança, PA, Brasil). Acta Botânica Brasileira, v. 22, n. 3, p. 626-636, 2008.

SVARSTADA, H.; PETERSENB, L. K.; ROTHMANC, D.; SIEPELD, H.; WÄTZOLD, F. Discursive biases of the environmental research framework DPSIR. Land Use Policy, n. 25, p. 116-125, 2008.

TRIGO, L.G.G.; MAZARO, R. Movimentos Globais e Cenários em Turismo: uma realidade dinâmica, uma viagem ao futuro. Turismo em Análise, v. 23, n. 3, p. 486-508, 2012.

TSCHERNING, K.; HELMING, K.; KRIPPNER, B.; SIEBER, S.; PALOMA, S.G. Does research applying the DPSIR framework support decision making?. Land Use Policy, n. 29, p. 102-110, 2012.

USHER, M. Landscape sensitivity: from theory to practice. CATENA, v. 42, n. 2-4, p. 375383, 2001. 
Glauce Vitor da Silva: Universidade do Estado do Pará, Belém, PA, Brasil.

Email: glaucevitor@yahoo.com.br

Link para o currículo Lattes: http://lattes.cnpq.br/0491000360565155

Altem Nascimento Pontes: Universidade do Estado do Pará, Belém, PA, Brasil.

Email: altempontes@hotmail.com

Link para o currículo Lattes: http://lattes.cnpq.br/5993352890364998

Alexandre Macedo Pereira: Universidade Federal do Rio Grande, Rio Grande, RS, Brasil.

Email: c.cpa2008@hotmail.com

Link para o currículo Lattes: http://lattes.cnpq.br/1811131513642380

Aline Maria Meiguins de Lima: Universidade Federal do Pará, Belém, PA, Brasil. Email: ameiguins@ufpa.br

Link para o currículo Lattes: http://lattes.cnpq.br/6572852379381594

Data de submissão: 04 de fevereiro de 2013

Data de recebimento de correções: $1^{\circ}$ de maio de 2013

Data do aceite: 14 de maio de 2013

Avaliado anonimamente 